\title{
Inheritance and Molecular Mapping of Tight-placenta Gene and Seed Traits in Chinese Hami Melon 'Queen'
}

\author{
Xuefei Ning, Xianlei Wang, Zhijie Yu, Simeng Lu, and Guan $\mathbf{L i}^{\mathbf{1}}$ \\ Department of Life Science and Technology, Xinjiang University, No. 14 \\ Sheng Li Road, Urumqi 830046, China
}

Additional index words. Cucumis melo seed trait, wave seed gene, genetic linkage map, quantitative trait locus

\begin{abstract}
Hami melon 'Queen' (Cucumis melo ssp. melo var. ameri Pangalo) is the most widely cultivated and exported type of melon in Xinjiang Province, Northwest China. We previously found the unique traits of Hami melon 'Queen' for wave seeds and tightplacenta fruits. An analysis of the inheritance showed that these traits were controlled by two recessive genes wave seed (ws) gene and tight-placenta (tp) gene, respectively. Here, to identify these two traits and melon seed-related traits, segregation populations including $\mathrm{BC}_{1}$ and $\mathrm{F}_{2}$ derived from a cross between 'Queen' $\left(\mathrm{P}_{1}\right)$ and MR-1 $\left(\mathrm{P}_{2}\right)$ were used as mapping populations. Eighty-seven simple sequence repeat (SSR) markers were used in map construction of $\mathrm{BC}_{1} \mathrm{P}_{1}$ population, and as a result, ws and $t p$ were identified on linkage group 1. Analysis of quantitative trait locus (QTL) referring seed traits showed that QTL ss1.1 for seed shape (SS) and QTL sl1.1 for seed length (SL) were located at LG 1, supported by likelihood of odds (LODs) of 15.6 and 13.4, respectively, and both linked with ws. Subsequently, the genetic linkage and parental re-sequence analysis were constructed for fine mapping $w s$ and $t p$. Genetic analysis showed that $w s$ and $t p$ were located in CM3.5_scaffold00060 on LG 1, flanked by InDelchr1-3241 and InDelchr13233. The 80.9-kb physical distance of this region included 11 candidate genes. Among them, MELO3C023549 and MELO3C023551 could be candidates for $w s$ and $t p$ by sequence alignment and allelic variation survey in parental lines. MELO3C023549 was predicted to encode an MYB46-like transcription factor related to positive regulation of secondary cell wall biogenesis. MELO3C023551 was annotated to encode a cellulose synthase A (CESA) associated with cellulose biosynthetic process.
\end{abstract}

Melon (C. melo L.; $2 n=2 x=24)$, a major economic fruit crop, is cultivated extensively in tropical and subtropical regions. Hami melon 'Queen' (C. melo ssp. melo var. ameri Pangalo) is the most widely cultivated and exported type of melon in Xinjiang Province, Northwest China. The production of sweet Hami melon benefits from the climate conditions there, including dry climate, large fluctuation of daily temperature, strong sunshine, and long sunshine duration in summer. Xinjiang Hami melon enjoys great reputation worldwide because of its unique flavor and high sugar content (Ning et al., 2014b).

Present genetic research on melon was focused on fruit size, quality traits (Díaz et al., 2014; Ramamurthy and Waters, 2015; Wang et al., 2016), plant morphology (Gao et al., 2014; Hwang et al., 2014; Zhu et al.,

Received for publication 5 Mar. 2018. Accepted for publication 16 Apr. 2018.

This work was supported by the Xinjiang Graduate Research and Innovation (XJGRI2014035), the National Natural Science Funding of China (31660297).

We thank National Melon Engineering and Technology Research Center, Xinjiang, China, for providing field and technical assistance for melon materials cultivating.

${ }^{1}$ Corresponding author. E-mail: guanlixju@163. com.
2011), and mapping resistance genes to different biotic stresses (Argyris et al., 2015a; Daley, 2014; Guiuaragonés et al., 2014; Li et al., 2017; Zhang et al., 2013). However, there are also many reports about various effects in melon seeds recently. Ashfak et al. (2014) found that melon seed oil consisted of moderate amount of unsaturated fatty acid and deoiled seed cake contained significant amounts of minerals $(\mathrm{N}, \mathrm{P}$, $\mathrm{K}$, and Ca). Lei and Kang (2013) indicated that hexane extract from melon seed could be used as a potent alternative for controlling type 2 diabetes in in vitro studies. In addition, melon seed traits could also be used as botanical classification factors. A significant correlation between melon seed traits and botanical classification were reported by Sabato et al. (2015) and Tanaka et al. (2016). Based on these positive effects, the information on melon seed traits may contribute to increasing the commercial values of melons and promote the development of melon industry.

Hagiwaea and Kamimura (1936) found that white seed testa color (vs. yellow) was controlled by one single dominant gene (symbol $W t-2$ ) which was present in PI 414723. Périn et al. (2002) reported that pine-seed shaped (vs. flat) traits were controlled by a single recessive gene (symbol pin). We previously found the wave seed and tight-placenta fruit of melon 'Queen', which were not found in most melon accessions. Tight-placenta fruit trait means that the placenta is uneasily separated from mesocarp at the maturing period. Specifically, 'Queen' melon seeds embedded into the flesh as a result of locular tissue degeneration (Fig. 1). Moreover, seeds separated from the melon 'Queen' placenta exhibit wave phenotype, which is also different from other melon accessions. Such unique traits of 'Queen' offer an opportunity to study the underlying mechanism of seed and placenta formation in melon.

To date, many linkage maps from different populations have been constructed and reported in melons (Obandoulloa et al., 2009; Perchepied et al., 2005; Tomason et al., 2013; Wang et al., 2016; Yuste-Lisbona et al., 2011). Among them, the integrated melon map was constructed by Diaz et al. (2011) using a variety of molecular markers. After the genome of melon (DHL92) has been sequenced, an improved anchoring of the assembled melon genome was published (Argyris et al., 2015b; Garciamas et al., 2012). The consensus ICuGI genetic map was also anchored to the reference genome of melon (DHL92) (Diaz et al., 2015). These studies not only facilitate comparative mapping in melon between past and new studies but also make it easier to analyze marker locus associated with target trait. With the development of next-generation sequencing techniques, linkage maps combined with whole-genome approach have been widely used to locate traits or QTLs and identify candidate genes ( $\mathrm{Hu}$ et al., 2017; Liu et al., 2016; Natarajan et al., 2016; Tian et al., 2016; Yao et al., 2017).

In this context, tight-placenta and seed traits were studied by using genetic mapping and parent re-sequence. Our objectives were to 1) study the inheritance of wave seed and tight-placenta fruit; 2) identify the QTL associated with seed weight (SW), seed width (SD), SL, and SS, and study the relationship between the tight-placenta trait and seed traits; and 3) fine map and predict candidate genes controlling wave seed and tight-placenta traits.

\section{Materials and Methods}

Plant materials and genomic DNA extraction. Two melon accessions, 'Queen' $\left(\mathrm{P}_{1}\right)$ and MR-1 $\left(\mathrm{P}_{2}\right)$, were used as parents in this study. 'Queen' bears wave seeds, smallwidth fruit cavity, and tight-placenta fruits, whereas MR-1 produces larger width fruit cavity, untight-placenta fruits, and glossy seeds (Fig. 1). These two parental lines were maintained as pure lines in the field at the National Melon Engineering and Technology Research Center (NMETRC), Xinjiang. MR-1 (female parent) were crossed with 'Queen' (male parent), and $F_{1}$ individuals were backcrossed with recurrent parent (female parent) to generate $\mathrm{BC}_{1} \mathrm{P}_{1}$ (consisting of 260 plants) and $\mathrm{BC}_{1} \mathrm{P}_{2}$ (consisting of 200 plants). The $\mathrm{F}_{1}$ plants were self-pollinated to produce an $\mathrm{F}_{2}$ population that consisted of 800 individuals. These experiments were conducted in the field of NMETRC in the Summer of 2012 and 2014. A total of $134 \mathrm{BC}_{1} \mathrm{P}_{1}$ plants were used to map 

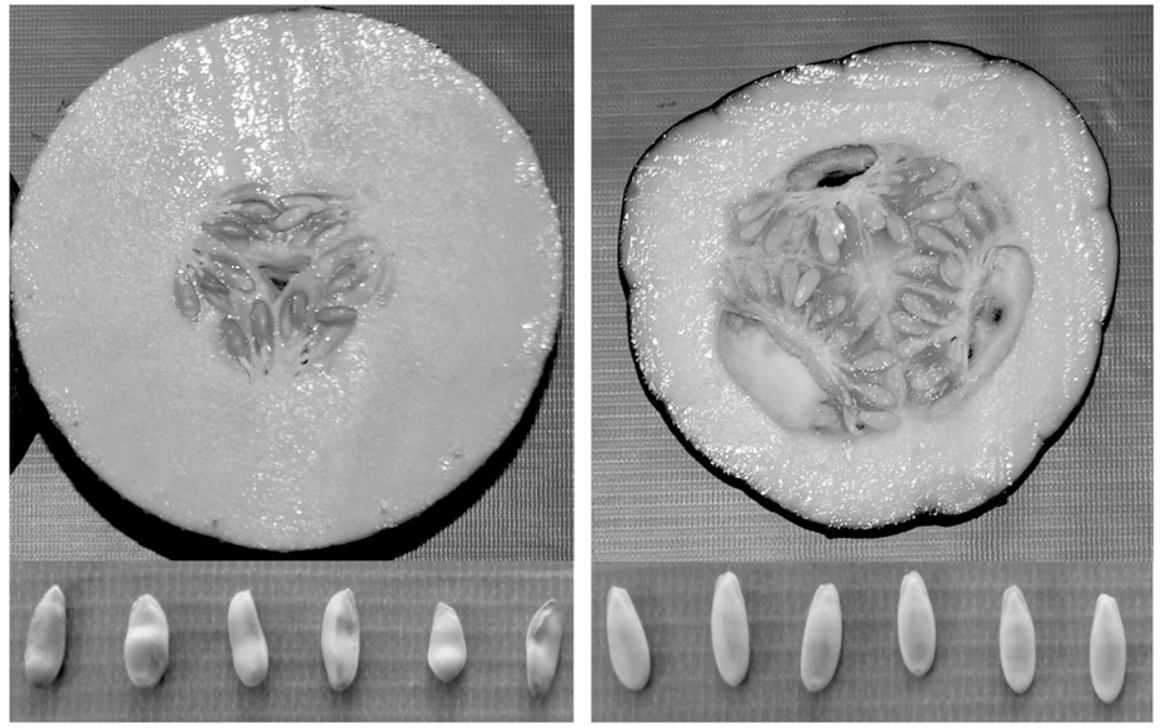

A Queen

B MR-1

Fig. 1. (A) Tight-placenta and wave seed characteristics of the line 'Queen'. (B) Untight-placenta and glossy seed characteristics of the line MR-1.

tight placenta and seed traits in the Summer of 2013 and $800 \mathrm{~F}_{2}$ plants were used to fine map $t p$ and $w s$ genes in the Summer of 2015.

Genetic analysis and scoring for phenotypic traits. Phenotypic data of wave seed and tight-placenta fruit traits were collected from $\mathrm{P}_{1}, \mathrm{P}_{2}, \mathrm{~F}_{1}$, and $\mathrm{BC}_{1} \mathrm{P}_{1}$ in 2013. The phenotypic data of $\mathrm{F}_{2}, \mathrm{BC}_{1} \mathrm{P}_{1}$, and $\mathrm{BC}_{1} \mathrm{P}_{2}$ for wave seed and tight-placenta fruit traits were investigated in 2015. Data of wave seed and tight-placenta fruit traits were categorized as nonmetric data. Single-melon seeds were classified by visual inspection as wave seeds or glossy seeds. The surface of the wave seed is wrinkled, whereas the surface of glossy seed is flattened (Fig. 1). Similarly, singlemelon fruits were scored for tight-placenta fruit trait by visual inspection. Tight-placenta fruit means that the placenta is closely integrated with mesocarp as the 'Queen'. The segregation ratios of the $\mathrm{F}_{2}$ and $\mathrm{BC}_{1}$ populations were analyzed with a $\chi^{2}$ test using SAS software.

Data of SW, SD, SL, and SS were categorized as quantitative data. Data for each trait in the mapping population were measured using three replications. One hundred and twenty-eight $\mathrm{BC}_{1} \mathrm{P}_{1}$ individuals were used to measure SW, SL, and SD. For SW (g), a random sample of 30 seeds was taken for each individual plant. For average SL and SD $(\mathrm{cm})$, a random sample of 10 seeds was quantitatively evaluated for each individual plant using ImageJ software. The ratio of SS is defined as SL divided by SD. The average value was used for the analysis. Statistical analysis of the data was performed using GraphPad Prism 6 (http://www.graphpad. $\mathrm{com} / \mathrm{prism} /$ ). The phenotypic correlation for seed size traits was obtained using the Pearson's correlation coefficient.

DNA isolation and molecular marker development. Genomic DNA was extracted from fresh melon leaves by the cetyltrimethylammonium bromide method (Porebski et al., 1997) with minor modifications. The purified DNA was diluted to $100 \mathrm{ng} \cdot \mu \mathrm{L}^{-1}$. A total of 499 SSR markers were selected from published sources (Chiba et al., 2003; DaninPoleg et al., 2000; Diaz et al., 2011, 2015; Fernandezsilva et al., 2008; Fukino et al., 2007; Gonzalo et al., 2005; Harel-Beja et al., 2010; Ritschel et al., 2004) or from http:// www.melonomics.net. Several new melon SSR and InDel primers were designed in the target region according to the resequencing data of two parent lines (Supplemental Tables 1 and 3). The genome of the melon accession DHL92 was downloaded from http://www.melonomics.net (version $\mathrm{CM}_{-}$ 3.5.1) and used as a reference genome. Resequencing of 'Queen' and MR-1 was performed at $\approx 20 \times$ coverage over the whole genome using the Illumina HisEq 2000 platform with the constructed paired-end sequence libraries at the Biomarker (Beijing, China). PCR amplification was performed in a thermal cycler (BIO-RAD C1000) with the following protocol: $94{ }^{\circ} \mathrm{C}$ for $3 \mathrm{~min} ; 35$ cycles of $94{ }^{\circ} \mathrm{C}$ for $30 \mathrm{~s}, 55{ }^{\circ} \mathrm{C}$ for $30 \mathrm{~s}$, $72{ }^{\circ} \mathrm{C}$ for $30 \mathrm{~s}$; and $72{ }^{\circ} \mathrm{C} 10 \mathrm{~min}$. Finally, the PCR products were separated on $32 \times 38 \times$ $0.04-\mathrm{cm}^{3} 6 \%$ denaturing polyacrylamide gels and stained with silver.

Linkage map construction. According to Lander et al. (1987), the heterozygous bands or the glossy seed/untight-placenta fruit of $\mathrm{BC}_{1} \mathrm{P}_{1}$ plants were recorded as " $\mathrm{H}$," the homozygous bands or the wave seed/tightplacenta fruit plants as " "A," and unclear or missing data as "-." For $F_{2}$ population, the band pattern of the maternal parent ('Queen') was denoted as "A," that of the paternal parent (MR-1) as " "B," and the heterozygous band as "H." The $\mathrm{F}_{2}$ population with wave seed/tight-placenta fruit as the 'Queen' was denoted as "A" and that with glossy seed/ untight-placenta individual as the MR-1 was denoted as "HB."

Phenotypic data, along with SSR and InDel analyses, were combined for linkage analysis using QTL IciMapping V4.1 (http:// www.isbreeding.net). Recombination units were converted into genetic distances based on Kosambi function (Kosambi, 1944). Markers were associated with minimum LODs $\geq 3.0$ and maximum distance $\leq 50.0$ centimorgan (cM). Finally, linkage maps were visualized using MapChart 2.2 (Voorrips, 2002). Gene prediction was performed according to the melon genome automated annotation database (https://melonomics. net). Gene annotation and analysis were conducted with the BLAST search on the published NR (nr database), SwissProt (Deng et al., 2006), GO (Gene ontology; Ashburner et al., 2000), COG (Clusters of orthologous groups of proteins; Tatusov et al., 2000), and KEGG databases (Kyoto encyclopedia of genes and genomes; Kanehisa et al., 2004).

QTL detection. QTLs regulating SW, SD, $\mathrm{SL}$, and SS were analyzed using phenotypic score and SSR marker data from the $\mathrm{BC}_{1} \mathrm{P}_{1}$ generations. Composite interval mapping was used for QTL detection. The window size was set at $5.0 \mathrm{cM}$ and the walk speed at $1.0 \mathrm{cM}$. Genome-wide significance thresholds were estimated by 1000 permutations to declare significant QTLs with a type-I error rate of 0.05 (Churchill and Doerge, 1994). Finally, QTLs were as presented by WinQTLCart 2.5 (Wang et al., 2012).

\section{Results}

Genetic analysis of wave seed and tightplacenta fruit traits. Fifteen $\mathrm{F}_{1}$ individuals, generated by crossing MR-1 with 'Queen', showed glossy seeds and untight-placenta fruits. In the $\mathrm{BC}_{1} \mathrm{P}_{1}$ population, 63 of 134 individuals showed glossy seeds and 71 showed the wave seeds. Sixty-nine of 134 individuals showed untight-placenta fruits and 65 showed the tight-placenta fruits. Segregation ratios were confirmed to be $1: 1$ by $\chi^{2}$ test. Wave seeds and tight-placenta plants were never observed in $\mathrm{BC}_{1} \mathrm{P}_{2}$ population. Furthermore, the 736 plants of the $\mathrm{F}_{2}$ population segregated into a glossy-to-wave seed/untight-to-tight placenta ratio of $3: 1$ (Table 1). These results indicated that the wave seed and tight-placenta traits were controlled by two single recessive genes, and these two genes were named $w s$ and $t p$. Interestingly, the phenotypic data suggested that the seeds of tight-placenta fruits were prone to be wave seeds. For the cosegregation data of the $\mathrm{BC}_{1} \mathrm{P}_{1}$ population, 63 individuals showed glossy seeds and untight-placenta fruits and 65 showed wave seeds and tightplacenta fruits. Six individuals showed wave seeds and untight-placenta fruits. For the cosegregation data of the $F_{2}$ population, 534 individuals showed glossy seeds and untightplacenta fruits and 188 showed wave seeds and tight-placenta fruits. Three individuals showed wave seeds and untight-placenta 
fruits, whereas 11 individuals showed glossy seeds and placenta fruits. The cosegregation rates of these two traits were $96 \%$ and $98 \%$ in $\mathrm{BC}_{1} \mathrm{P}_{1}$ and $\mathrm{F}_{2}$ populations, respectively (Table 1). Therefore, the seed wave trait was supposed to be related with the tightplacenta fruit trait.

Mapping of wave seed and tight-placenta genes. A total of 449 SSR marker primers were tested to identify the polymorphism between the parents. Eighty-seven of 449 markers amplified clear, reproducible, and specific polymorphism straps, which were used in map construction of $\mathrm{BC}_{1} \mathrm{P}_{1}$ population. According to the molecular marker data and phenotype scores, 10 polymorphic markers were identified to be linked with the two traits. The genotypes of these 10 markers and the phenotype data of the two traits from $\mathrm{BC}_{1} \mathrm{P}_{1}$ plants were used to calculate a linkage map (Supplemental Table 1).
The wave seed and tight-placenta traits were mapped on LG 1 as monogenic traits. The $t p$ and $w s$ genes were located at 25.7 and $33.0 \mathrm{cM}$ and flanked by the markers ECM110 and CMMS22-2, respectively (Fig. 2A). The genetic distance between $t p$ and $w s$ gene locus was $7.3 \mathrm{cM}$. These results were in agreement with the hypothesis that the tightplacenta trait was related with the wave seed trait.

Phenotypic evaluations of seed size traits and QTL analysis. Mean value, SD, skewness, and kurtosis for seed size traits measured in $128 \mathrm{BC}_{1} \mathrm{P}_{1}$ individuals were calculated (Table 2). Continuous distributions were observed in all four seed traits, and the phenotype data of these traits followed a normal distribution based on the values of skewness and kurtosis statistics. The frequency distribution of the $\mathrm{BC}_{1} \mathrm{P}_{1}$ individuals for each trait is shown in Supplemental Fig. 1.
Pearson's correlations for seed size traits are given in Supplemental Table 2. Significant correlations for most trait pairs were observed, except for the SL-SD and SW-SS pair in correlation analysis.

Genomic regions associated with SD, SL, SS, and SW were identified through QTL analysis, which involved 87 polymorphic SSR markers and two phenotype makers (Supplemental Fig. 2). Eight QTLs for those quantitative seed traits were located, based on a permutation test at $P=0.05$, at the whole-genome level (Table 3), a major QTL for SS, ss 1.1, was located at LG 1, with an LOD of 15.6, and ss 1.1 was linked with wave seed trait. Another major QTL for SL, sll.1 on LG 1, was also linked with wave seed trait, with an LOD of 13.4 (Fig. 3). The seed width was associated with four minor QTLs at LG 3, 5,8 , and 12 , respectively. Two minor QTLs related to SW were detected on LG 1 and 6 , in

Table 1. Chi-square goodness-of-fit test ratios of wave seed/tight-placenta trait in $\mathrm{BC}_{1}$ and $\mathrm{F}_{2}$ populations.

\begin{tabular}{|c|c|c|c|c|c|c|}
\hline Populations & $\begin{array}{c}\text { Total plants } \\
\text { number }\end{array}$ & $\begin{array}{c}\text { Number of glossy } \\
\text { seed/untight-placenta } \\
\text { individuals }\end{array}$ & $\begin{array}{c}\text { Number of wave } \\
\text { seed/tight-placenta } \\
\text { individuals }\end{array}$ & $\begin{array}{l}\text { Expected } \\
\text { ratio }\end{array}$ & $\begin{array}{l}\text { Wave seed/tight-placenta } \\
\text { trait } \chi^{2 z}\end{array}$ & $\begin{array}{c}\text { Cosegregation rates } \\
\text { of } w s \text { and } t p(\%)\end{array}$ \\
\hline$\overline{\mathrm{F}_{1}(2013)}$ & 15 & $15 / 15$ & $0 / 0$ & & & \\
\hline $\mathrm{BC}_{1} \mathrm{P}_{1}(2013)$ & 134 & $63 / 69$ & $71 / 65$ & $1: 1$ & $0.48 / 0.12$ & 96 \\
\hline $\mathrm{BC}_{1} \mathrm{P}_{2}(2013)$ & 96 & $96 / 96$ & $0 / 0$ & & & \\
\hline $\mathrm{F}_{2}(2015)$ & 736 & $546 / 536$ & $190 / 200$ & $3: 1$ & $0.61 / 0.17$ & 98 \\
\hline
\end{tabular}

${ }^{\mathrm{z}} \chi^{2}>\chi_{0.05}^{2}=3.84$ is considered significant.

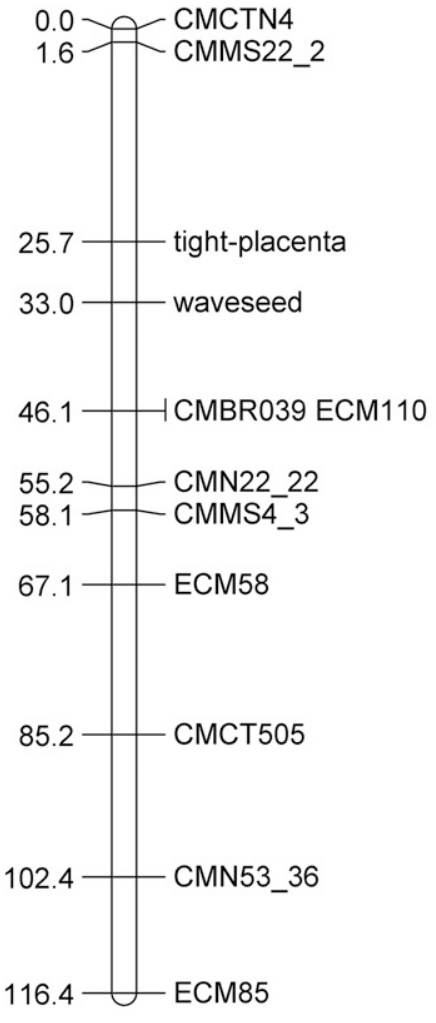

A

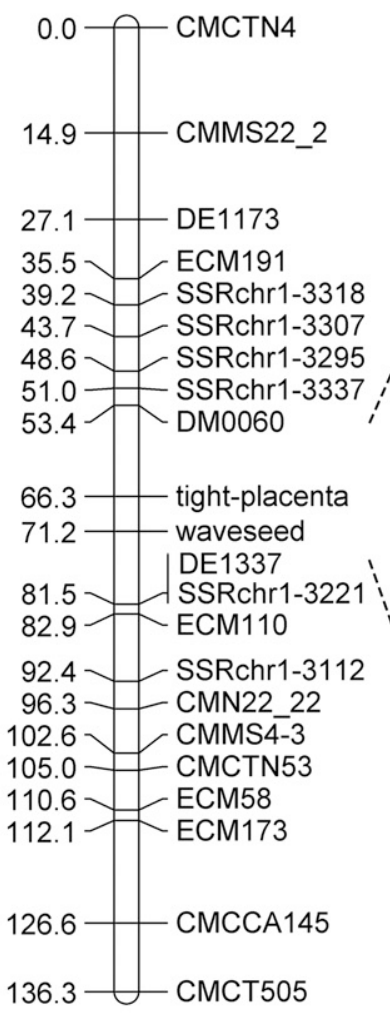

B

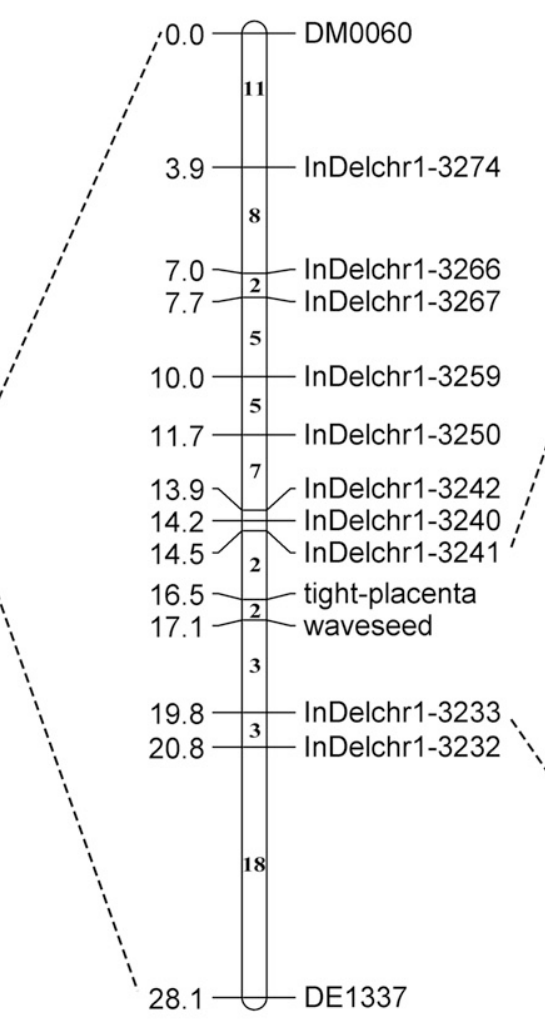

C

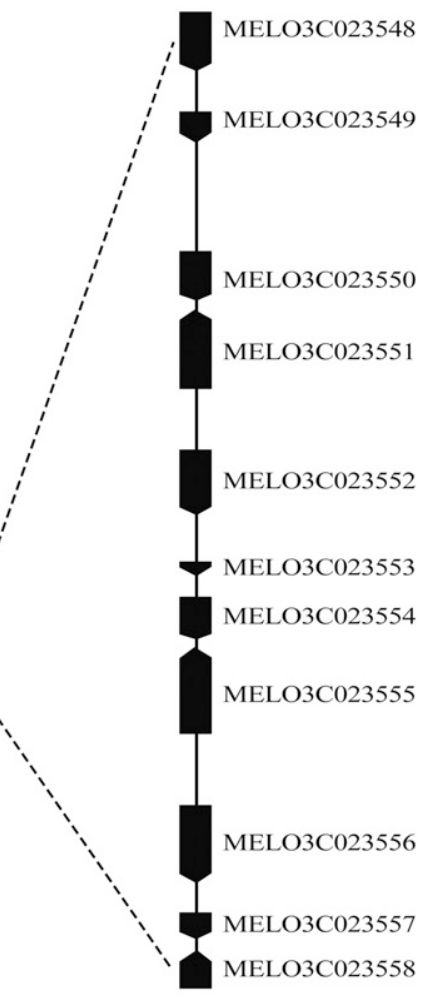

D

Fig. 2. Fine genetic mapping of wave seed (ws) and tight-placenta ( $t p)$ genes. (A) Linkage map of $w s$ and $t p$ genes constructed using the $128 \mathrm{BC}_{1} \mathrm{P}_{1}$ populations of MR-1 and 'Queen'. The markers are shown at the right of LG 1 and the distances among them are indicated in centimorgans on the left. (B) Preliminary further mapping for $w s$ and $t p$ based on $96 \mathrm{~F}_{2}$ plants. (C) Fine mapping including the $w s$ and $t p$ locus in the $736 \mathrm{~F}_{2}$ plants. Numbers above the chromosome are recombinants at each interval. (D) The genomic region between InDelchr1-3241 and InDelchr1-3233 (80.9 kb) in which 11 genes were predicted. 
Table 2. Descriptive statistics of phenotype data of two parents and $\mathrm{BC}_{1}$ mapping population.

\begin{tabular}{|c|c|c|c|c|c|c|c|c|}
\hline \multirow[b]{2}{*}{ Trait $^{z}$} & \multicolumn{2}{|c|}{ Parents } & \multicolumn{6}{|c|}{$\mathrm{BC}_{1}$ mapping population } \\
\hline & Queen & MR-1 & Min. & Max. & Mean & SD & Skewness & Kurtosis \\
\hline$\overline{\mathrm{SS}}$ & $2.24 \pm 0.11$ & $2.59 \pm 0.23$ & 1.87 & 3.05 & 2.48 & 0.28 & -0.01 & -0.59 \\
\hline $\mathrm{SL}(\mathrm{cm})$ & $0.95 \pm 0.05$ & $1.21 \pm 0.07$ & 0.91 & 1.39 & 1.18 & 0.12 & -0.23 & -0.91 \\
\hline $\mathrm{SD}(\mathrm{cm})$ & $0.43 \pm 0.02$ & $0.47 \pm 0.03$ & 0.44 & 0.56 & 0.48 & 0.03 & 0.56 & -0.06 \\
\hline SW (g) & $1.17 \pm 0.07$ & $1.01 \pm 0.10$ & 0.49 & 1.22 & 0.89 & 0.14 & -0.22 & 0.45 \\
\hline
\end{tabular}

${ }^{\mathrm{z}} \mathrm{SL}, \mathrm{SD}$, and SW indicate seed length, width, and weight, respectively; SS indicate length-to-width ratio.

Table 3. QTLs affect seed characteristics in the $\mathrm{BC}_{1} \mathrm{P}_{1}$ segregated progeny of MR-1 and 'Queen'.

\begin{tabular}{|c|c|c|c|c|c|c|}
\hline Traits & $\begin{array}{l}\text { Quantitative } \\
\text { trait loc }\end{array}$ & $\begin{array}{l}\text { Linkage } \\
\text { group }\end{array}$ & $\begin{array}{l}\text { Locus closest to } \\
\operatorname{max.~LOD}\end{array}$ & Position (cM) & Max. LOD & Additive \\
\hline Seed shape & ss 1.1 & LG 1 & Wave seed & 33.0 & 15.6 & -0.41 \\
\hline Seed length & sll.1 & LG 1 & Wave seed & 33.0 & 13.4 & -0.20 \\
\hline \multirow[t]{4}{*}{ Seed width } & $s d 3.1$ & LG 3 & MU4452-ECM205 & 74.2 & 2.0 & 0.02 \\
\hline & $s d 5.1$ & LG 5 & ECM92 & 15.7 & 2.2 & -0.01 \\
\hline & $s d 8.1$ & LG 8 & $\mathrm{TJ} 2$ & 35.6 & 1.5 & 0.02 \\
\hline & $s d 12.1$ & LG 12 & GCM206-DE1851 & 67.0 & 2.2 & 0.03 \\
\hline \multirow[t]{2}{*}{ Seed weight } & $s w 1.1$ & LG 1 & Wave seed & 33.0 & 2.0 & -0.10 \\
\hline & sw6.1 & LG 6 & ECM52 & 104.1 & 1.6 & 0.11 \\
\hline
\end{tabular}

${ }^{\mathrm{z}}$ Additive: phenotypic variation of additive effect. $\mathrm{LOD}=$ likelihood of odd; $\mathrm{cM}=$ centimorgan.

which the sw1.1 on LG 1 was also linked with wave seed trait, with an LOD of 2.0.

Fine genetic and physical mapping of the wave seed and tight-placenta locus. After LG 1 was identified as the target genomic region of $w s$ and $t p$, new SSR markers were designed, of which 13 were polymorphic between two parental lines (Supplemental Table 1). A linkage map was developed with the 20 SSR markers (including seven markers from $\mathrm{BC}_{1} \mathrm{P}_{1}$ ) and $96 \mathrm{~F}_{2}$ individuals, which is shown in Fig. 2B. The SSR markers DM0060 and DE1337 were closest to $t p$ and $w s$ locus, flanking the gene at genetic distances of 12.9 and $10.0 \mathrm{cM}$, respectively. The interval between the two markers was $555 \mathrm{~kb}(32,289,526-32,845,288 \mathrm{bp})$.

An enlarged mapping population comprising $736 \mathrm{~F}_{2}$ plants was used for fine mapping. A total of 66 recombinants were identified between SSR markers DM0060 and DE1337 in the 555-kb region. To further narrow down the candidate region for $t p$ and $w s$ locus, 19 new InDel markers were designed by comparing the whole-genome resequencing data. Ten of these showed clear, stable, and polymorphic amplifications between the parents (Supplemental Table 3). Then, the fine linkage map was developed with 66 recombinant plants and 12 markers (two SSR and 10 InDel markers), and the number of recombinants between adjacent markers is presented in Fig. 2C. Linkage analysis revealed that the InDel markers InDelchr1-3241 and InDelchr1-3233 were closest to $t p$ and $w s$, flanking the gene at genetic distances of 2.0 and $2.7 \mathrm{cM}$, which was $\approx 80.9-\mathrm{kb}$ region.

Candidate gene prediction and annotation in the ws and tp mapping region. Genomic DNA regions between the two flanking markers InDelchr1-3241 and InDelchr1-3233 were annotated in the melon genome database (https://melonomics.net). In the $80.9-\mathrm{kb}$ physical distance between InDelchr1-3241 and InDelchr1-3233, there were 11 predicted genes on CM3.5_scaffold00060 (Fig. 2D). Information about position and predicted functions of each gene is shown in Supplemental Table 4. To pinpoint possible candidate genes of $w s$ and $t p$, we first looked into sequence variations in 11 predicted genes by alignment of the genomic DNA sequence of MR-1 to 'Queen'. No SNP or InDel variations were found in the exon region of coding sequence.

To further determine whether there is marker-phenotype association for $w s$ and tp genes in this $80.9-\mathrm{kb}$ region, sequence alignment were conducted between 'Queen' and MR-1. A total of 15 unique SNP locus and 17 unique InDel variations in 'Queen' were identified (Supplemental Tables 5 and 6). According to gene prediction annotation, these SNP and InDel variations were located in MELO3C023548, MELO3C023549, MELO3C023550, MELO3C023551, MELO3C023554, and MELO3C023555. The InDel (3-bp insertionChr.1:32354792) observed in MELO3C023555 and InDel (1-bp deletion-Chr.1: 32408632) observed in MELO3C023548 caused UTR_3 PRIME and UTR 5_PRIME region variants, respectively. The SNP (nucleotide transition of $\mathrm{G}$ to T-Chr.1: 32392799) and InDel (8 bp deletion-Chr.1: 32393077) were identified in the upstream of MELO3C023550. Two InDels (1-bp deletion) were observed in the upstream MELO3C023554.

Most variations, including 14 SNPs and 11 InDel variations were found in MELO3C023549, which means the MELO3C023549 in 'Queen' may be different from that of other melon lines. MELO3C023549 was predicted to encode a member of transcription factor MYB similar to an MYB46-like transcription factor that appeared to be related to positive regulation of secondary cell wall biogenesis (Supplemental Table 4). One InDel (33 bp DNA insertion-Chr.1: 32382245) was detected in the intron of MELO3C023551. In the DHL92 reference genome, this gene was $6244 \mathrm{bp}$ in length with 14 exons. This 33-bp insertion of 'Queen' was found in 105-bp intron region between exon 10 and exon 11 (scaffold00060: 1,260,215-1,260,320). MELO3C023551 was annotated to encode CESA catalytic subunit 3 (UDP forming) and related to cellulose biosynthetic process. Thus, we inferred that MELO3C023549 and MELO3C023551 were likely associated with wave seed and tightplacenta mutation in melon 'Queen'.

\section{Discussion}

We previously found an interesting phenomenon that melon 'Queen' bears tightplacenta fruits and wave seeds. Genetic analysis showed that these two traits were controlled by the recessive genes $w s$ and $t p$, respectively. In addition, the cosegregation rates showed that the tight-placenta trait was linked with the wave seed trait. This is the first report about $w s$ and $t p$ genes in melon.

A total of 449 SSR markers were screened, but only 87 SSR markers amplified polymorphism straps which were clear, reproducible, and specific. Fifteen polymorphic SSR markers were unable to amplify clear and specific polymorphism bands. The polymorphism level was $22.7 \%$ (102 of 449) between 'Queen' and MR-1 in this study. But this polymorphic ratio did not represent the polymorphism level of SSR markers between 'Queen' and MR-1 according to our other studies. MR-1 and 'Queen' were also used as parents to map QTL for downy mildew resistance (data unpublished). In that study, 537 SSR primers were tested and 168 (31.3\%) were polymorphic between MR-1 and 'Queen'. This polymorphic ratio was similar to that found between AR 5 and Harukei 3 (30.8\%) (Fukino et al., 2008), or polymorphism ratio between Edisto 47 and 'Queen' (30.5\%) (Ning et al., 2014a). But this polymorphism level was still lower than that found between the parents used to derive the PI_PS map (49.6\%) (Gonzalo et al., 2005). The lower polymorphism between 'Queen' and MR-1 can be attributed to their more similar genetic background.

Previous studies showed that the morphology traits of Cucurbitaceae seeds were quantitative traits generally controlled by multiple genes. Several QTLs associated with seed traits were detected on seven linkage groups in watermelon (Chi et al., 2017; Liu et al., 2014; Yi et al., 2014). QTL analysis of cucumber seed was concentrated on the five linkage groups (Chen et al., 2012; Wang et al., 2014). By using an $F_{2}$ population developed from melon Ano2 and K413, Wang et al. $(2011)$ found that several QTLs on LG 2, 5, 7, 8, 9, and 10 controlled SL, SD, and SW. Six QTLs for seed-related traits were detected on LG 1, 2, 5, and 8 in melon MR-1 and M1-15 (Ye et al., 2017). In this study, one major SL QTL and one major SS QTL, both linked with wave seed trait, were detected at LOD scores of 15.6 and 13.4, respectively. This result showed that wave seed shape had a significant impact on SL and SS traits during melon 'Queen' fruit development.

A total of 66 SSR and 19 InDel markers on LG 1 were used in this study (Supplemental Tables 1 and 3). Forty-seven of 66 SSRs were selected based on previously published 


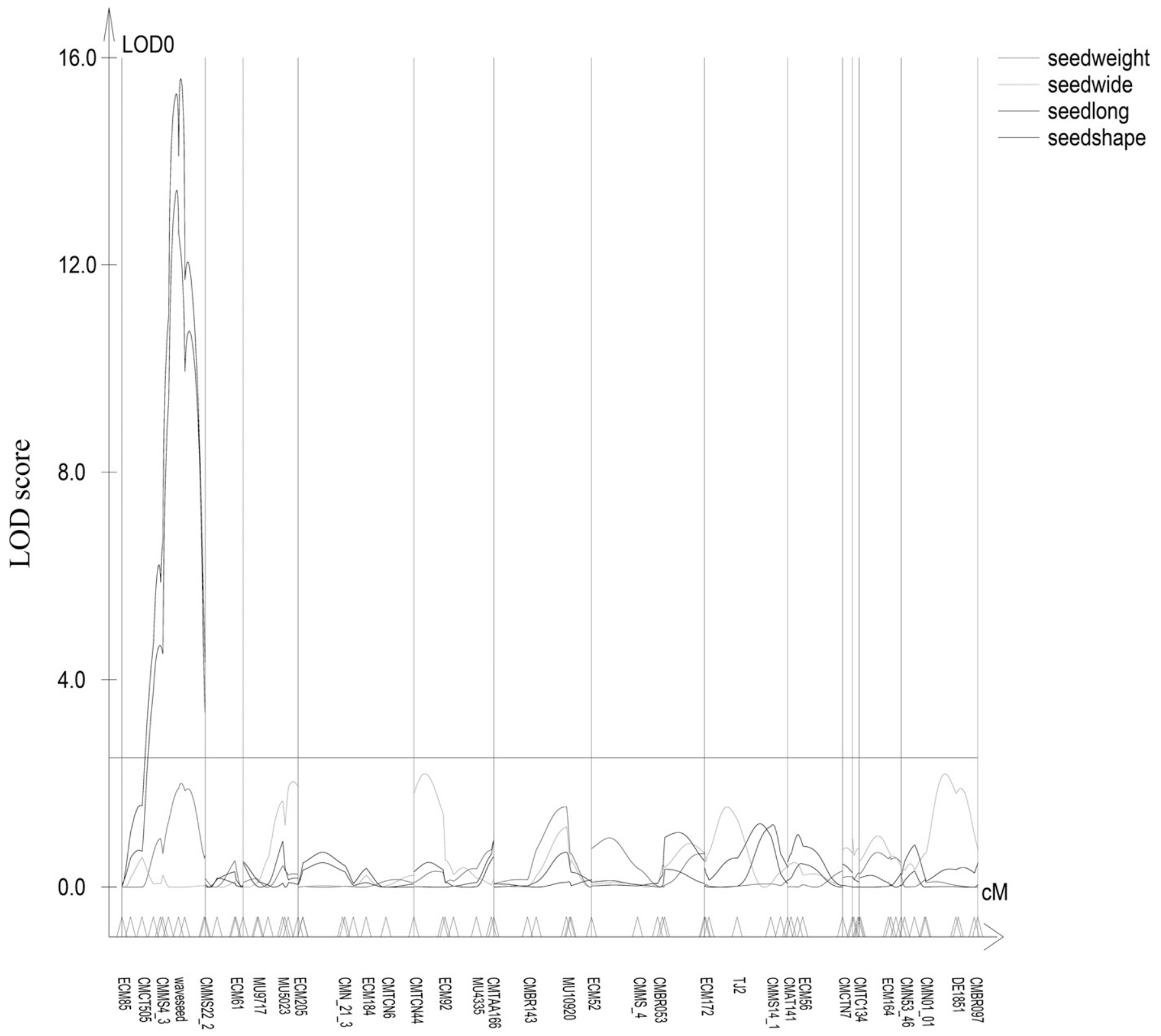

Fig. 3. QTLs for seed length (SL), width, shape, and weight detected on WinQTLCart 2.5. Mapping of quantitative trait locus (QTL) correlated with seed shape in LG I also identified significant QTL for SL in this region.

SSRs. Among them, four SSR markers ECM110, CMMS22-2, DM0060, and DE1337 were found linked with $w s$ and $t p$ locus. ECM110 and CMMS22-2 have been mapped in the ICuGI consensus and anchored to the melon genome (Diaz et al., 2011). In addition, DM0060 and DE1337 contributed by Syngenta have been reported with higher polymorphism information content of 0.49 and 0.64 , respectively (Diaz et al., 2015). Therefore, these four SSR markers located in QTL could be used for further research of seed traits in other melon species.

The $w s$ and $t p$ genes were delimited to an $80.9-\mathrm{kb}$ region that contained 11 genes and nine of them were annotated. MELO3C023549 and MELO3C023551 were inferred as the candidate genes for wave seed and tight-placenta mutation in melon 'Queen'. The sequence analysis of MELO3C023549 showed no unique SNPs or InDel variations of 'Queen' in CDS region, whereas most variations were found in upstream and downstream regions (Supplemental Tables 4 and 5). This MELO3C023549 was predicted to encode an MYB46-like transcription factor. MYB46 has been reported to regulate the biosynthesis of secondary wall, directly or cooperatively with downstream target transcription factors (Kim et al., 2013; Ko et al., 2012). Overexpression of MYB46 caused ectopic deposition of secondary walls in Arabidopsis (Ko et al., 2007, 2009). MELO3C023551 was annotated to encode a member of the class CESA. Many studies showed that CESAs involved in cellulose biosynthesis of plants and generation of primary and secondary cell wall biomass (Desprez et al., 2002, 2007; Liu et al., 2012; Persson et al., 2007; Taylor et al., 2003). Mutants of CESA4, CESA7, and
CESA8 caused the lack of the characteristic secondary thickening in xylem (Taylor et al., 2003; Wolf-Rüdiger et al., 2001). Mutants of CESA2, CESA5, and CESA9 resulted in lower cellulose content, loss of cell shape uniformity, and reduced radial wall integrity in Arabidopsis seedcoat epidermal cells (Mendu et al., 2011a, 2011b). Thus, MELO3C023549 and MELO3C023551 may be related to the secondary cell wall formation during melon seed development. Such unique phenomenon of $w s$ and $t p$ may be due to unusual expression of these genes, which resulted in ectopic deposition of cellulose on second secondary cell wall processes of melon seeds. The unusual development of the seed could then send a hormonal signal to the placenta, which leads to the different placenta development. Obviously, these possible explanations need to be verified by subsequent research. 
In the candidate $80.9-\mathrm{kb}$ region, there is another interesting predicted gene MELO3C023556T1, which was predicted to encode the member of the class polygalacturonase (PG). PG genes were found closely related to multiple cell separation events, including both abscission and dehiscence in Arabidopsis (Ogawa et al., 2009). Although no unique variation was detected by resequence in MELO3C023556T1, this annotated gene associated with cell wall biogenesis should also be studied further. Further research will be carried out to determine precisely the genes that confer the wave seed and tight-placenta traits in melon 'Queen'.

\section{Literature Cited}

Argyris, J.M., M. Pujol, A.M. Martín-Hernández, and J. Garcia-Mas. 2015a. Combined use of genetic and genomics resources to understand virus resistance and fruit quality traits in melon. Physiol. Plant. 155:4-11.

Argyris, J.M., A. Ruizherrera, P. Madrizmasis, W. Sanseverino, J. Morata, M. Pujol, S.E. Ramosonsins, and J. Garciamas. 2015b. Use of targeted SNP selection for an improved anchoring of the melon (Cucumis melo L.) scaffold genome assembly. BMC Genomics $16: 4-29$.

Ashburner, M., C.A. Ball, J.A. Blake, D. Botstein, H. Butler, J.M. Cherry, A.P. Davis, K. Dolinski, S.S. Dwight, and J.T. Eppig. 2000. Gene ontology: Tool for the unification of biology. The Gene Ontology Consortium. Nat. Genet. 25: 25-29.

Ashfak, H., M.H. Uddin, M.A. Mannan, S. Barua, and M.A. Hoque. 2014. Studies on the isolation, physico-chemical characterization and microbial activities of melon (Cucumis melo) seed oil. Carcinogenesis 8:1375-1383.

Chen, L.L., Z.W. Qin, X.Y. Zhou, M. Xin, and T. Wu. 2012. Molecular marker and genetic analysis of cucumber seed length. Chinese Agricultural Sci. Bul. 28:165-170. (in chinese with English abstr.).

Chi, Y.Y., P. Gao, Z.C. Zhu, F.S. Luan, L.I Guiying, and Y.U. Peng. 2017. The QTL analysis of fruit and seed associated traits in watermelon based on CAPS markers. Scientia Agricultura Sinica 50:1282-1293. (in chinese with English abstr.).

Chiba, N., K. Suwabe, T. Nunome, and M. Hirai 2003. Development of microsatellite markers in melon (Cucumis melo L.) and their application to major cucurbit crops. Breeding Sci. 53:21-27.

Churchill, G.A. and R.W. Doerge. 1994. Empirical threshold values for quantitative trait mapping. Genetics 138:963-971.

Daley, J.D. 2014. Mapping quantitative trait loci associated with Alternaria leaf blight resistance and elemental sulfur tolerance in melon. Clemson Univ., Clemson, SC, Diss.

Danin-Poleg, Y., N. Reis, G. Tzuri, and N. Katzir. 2000. Development and characterisation of microsatellite markers in Cucumis. Theor. Appl. Genet. 102:61-72.

Deng, Y., L.I. Jianqi, W.U. Songfeng, Y. Zhu, Y. Chen, and H.E. Fuchu. 2006. Integrated $\mathrm{nr}$ database in protein annotation system and its localization. Comput. Eng. 32:71-72.

Desprez, T., M. Juraniec, E.F. Crowell, H. Jouy, Z Pochylova, F. Parcy, H. Höfte, M. Gonneau, and S. Vernhettes. 2007. Organization of cellulose synthase complexes involved in primary cell wall synthesis in Arabidopsis thaliana. Proc. Natl. Acad. Sci. USA 104:15572-15577.
Desprez, T., S. Vernhettes, M. Fagard, G. Refrégier, T. Desnos, E. Aletti, N. Py, S Pelletier, and H. Höfte. 2002. Resistance against herbicide isoxaben and cellulose deficiency caused by distinct mutations in same cellulose synthase isoform CESA6. Plant Physiol. 128:482-490.

Diaz, A., M. Fergany, G. Formisano, P. Ziarsolo, J. Blanca, Z. Fei, J.E. Staub, J.E. Zalapa, H.E. Cuevas, and G. Dace. 2011. A consensus linkage map for molecular markers and quantitative trait loci associated with economically important traits in melon (Cucumis melo L.). BMC Plant Biol. 11:111-118.

Diaz, A., J. Forment, J.M. Argyris, N. Fukino, G. Tzuri, R. Harel-Beja, N. Katzir, J. Garcia-Mas, and A.J. Monforte. 2015. Anchoring the consensus ICuGI genetic map to the melon (Cucumis melo L.) genome. Mol. Breeding 35:188-195.

Díaz, A., B. Zarouri, M. Fergany, I. Eduardo, J.M. Alvarez, B. Picó, and A.J. Monforte. 2014 Mapping and introgression of QTL involved in fruit shape transgressive segregation into 'Piel de Sapo' melon (Cucucumis melo L.). PLoS One 9:1-12.

Fernandezsilva, I., I. Eduardo, J. Blanca, C. Esteras, B. Picó, F. Nuez, P. Arús, J. Garciamas, and A.J. Monforte. 2008. Bin mapping of genomic and EST-derived SSRs in melon (Cucumis melo L.). Theor. Appl. Genet. 118:139-150.

Fukino, N., T. Ohara, A.J. Monforte, M. Sugiyama, Y. Sakata, M. Kunihisa, and S. Matsumoto. 2008. Identification of QTLs for resistance to powdery mildew and SSR markers diagnostic for powdery mildew resistance genes in melon (Cucumis melo L.). Theor. Appl. Genet. 118:165-175.

Fukino, N., Y. Sakata, M. Kunihisa, and S. Matsumoto. 2007. Characterisation of novel simple sequence repeat (SSR) markers for melon (Cucumis melo L.) and their use for genotype identification. J. Hort. Sci. Biotechnol. 82:330-334.

Gao, X.W., X.F. Ning, Y.M. Wang, X.L. Wang, W.L. Yan, Z.Q. Zhang, and G. Li. 2014. Fine mapping of a gene that confers palmately lobed leaf $(p l l)$ in melon (Cucumis melo L.). Euphytica 200:337-347

Garciamas, J., A. Benjak, W. Sanseverino, M. Bourgeois, G. Mir, V.M. González, E. Hénaff, F. Câmara, L. Cozzuto, and E. Lowy. 2012. The genome of melon (Cucumis melo L.). Proc. Natl. Acad. Sci. USA 109:11872-11877.

Gonzalo, M.J., M.M.J. Oliver, A. Monfort, S.R Dolcet, N. Katzir, P. Arus, and A.J. Monforte. 2005. Simple-sequence repeat markers used in merging linkage maps of melon (Cucumis melo L.). Theor. Appl. Genet. 110:802-811.

Guiuaragonés, C., A.J. Monforte, M. Saladié, R.X. Corrêa, J. Garciamas, and A.M. Martínhernández. 2014. The complex resistance to cucumber mosaic cucumovirus (CMV) in the melon accession PI161375 is governed by one gene and at least two quantitative trait loci. Mol. Breeding 34:351-362.

Hagiwaea, T. and K. Kamimura. 1936. Crossbreeding experiments in Cucumis Melo. Tokyo Horticultural School Publication, Tokyo, Japan.

Harel-Beja, R., G. Tzuri, V. Portnoy, M. LotanPompan, S. Lev, S. Cohen, N. Dai, L. Yeselson, A. Meir, and S.E. Libhaber. 2010. A genetic map of melon highly enriched with fruit quality QTLs and EST markers, including sugar and carotenoid metabolism genes. Theor. Appl. Genet. 121:511-533.

Hu, Z., G. Deng, H. Mou, Y. Xu, L. Chen, J. Yang, and M. Zhang. 2017. A re-sequencing-based ultra-dense genetic map reveals a gummy stem blight resistance-associated gene in Cucumis melo. DNA Res. 0:1-10.
Hwang, J., J. Oh, Z. Kim, J.E. Staub, S.M. Chung, and Y. Park. 2014. Fine genetic mapping of a locus controlling short internode length in melon (Cucumis melo L.). Mol. Breeding 34:949-961.

Kanehisa, M., S. Goto, S. Kawashima, Y. Okuno, and M. Hattori. 2004. The KEGG resource for deciphering the genome. Nucl. Acids Res. 32:277-280.

Kim, W-C., J-Y. Kim, J-H. Ko, J. Kim, and K-H. Han. 2013. Transcription factor MYB46 is an obligate component of the transcriptional regulatory complex for functional expression of secondary wall-associated cellulose synthases in Arabidopsis thaliana. J. Plant Physiol. 170:1374-1378

Ko, J-H., W-C. Kim, and K-H. Han. 2009. Ectopic expression of MYB46 identifies transcriptional regulatory genes involved in secondary wall biosynthesis in Arabidopsis. Plant J. 60:649665.

Ko, J-H., W-C. Kim, J-Y. Kim, S-J. Ahn, and K-H. Han. 2012. MYB46-mediated transcriptional regulation of secondary wall biosynthesis. Mol. Plant 5:961-963.

Ko, J-H., S.H. Yang, A.H. Park, O. Lerouxel, and K-H. Han. 2007. ANAC012, a member of the plant-specific NAC transcription factor family, negatively regulates xylary fiber development in Arabidopsis thaliana. Plant J. 50:10351048.

Kosambi, D.D. 1944. The estimation of map distances from recombination values. Ann. Eugen. 12:172-175.

Lander, E.S., P. Green, J. Abrahamson, A. Barlow, M.J. Daly, S.E. Lincoln, and L. Newburg. 1987. MAPMAKER: An interactive computer package for constructing primary genetic linkage maps of experimental and natural populations. Genomics 1:174-181.

Lei, C. and Y.H. Kang. 2013. In vitro inhibitory effect of oriental melon (Cucumis melo L. var. makuwa Makino) seed on key enzyme linked to type 2 diabetes: Assessment of anti-diabetic potential of functional food. J. Funct. Foods 5:981-986.

Li, B., Y.L. Zhao, Q.L. Zhu, Z.P. Zhang, C. Fan, S. Amanullah, P. Gao, and F.S. Luan. 2017. Mapping of powdery mildew resistance genes in melon (Cucumis melo L.) by bulked segregant analysis. Scientia Hort. 220:160-167.

Liu, C.Q., P. Gao, and F.S. Luan. 2014. Construction of a genetic linkage map and QTL analysis of fruit-associated traits in watermelon. Scientia Agricultura Sinica 47:2814-2829. (in chinese with English abstr.).

Liu, X., Q. Wang, P. Chen, F. Song, M. Guan, L. Jin, Y. Wang, and C. Yang. 2012. Four novel cellulose synthase (CESA) genes from birch (Betula platyphylla Suk.) involved in primary and secondary cell wall biosynthesis. Intl. J. Mol. Sci. 13:12195-12212.

Liu, X.P., C. Yang, F.Q. Han, Z.Y. Fang, L.M. Yang, M. Zhuang, H.H. Lv, Y.M. Liu, Z.S. Li, and Y.Y. Zhang. 2016. Genetics and fine mapping of a yellow-green leaf gene ( $y g l-l)$ in cabbage (Brassica oleracea var. capitata $\mathrm{L}$.) Mol. Breeding 36:82-90.

Mendu, V., J.S. Griffiths, S. Persson, J. Stork, A.B. Downie, C. Voiniciuc, G.W. Haughn, and S. Debolt. 2011a. Subfunctionalization of cellulose synthases in seed coat epidermal cells mediates secondary radial wall synthesis and mucilage attachment. Plant Physiol. 157:441-453.

Mendu, V., J. Stork, D. Harris, and S. Debolt. 2011b. Cellulose synthesis in two secondary cell wall processes in a single cell type. Plant Signal. Behav. 6:1638-1643. 
Natarajan, S., H.T. Kim, S.K. Thamilarasan, K. Veerappan, J.I. Park, and I.S. Nou. 2016. Whole genome re-sequencing and characterization of powdery mildew disease-associated allelic variation in melon. PLoS One 11: e0157524-e0157543.

Ning, X.F., X.L. Wang, X.W. Gao, Z.Q. Zhang, L.H. Zhang, W.L. Yan, and G. Li. 2014a. Inheritances and location of powdery mildew resistance gene in melon Edisto47. Euphytica 195:345-353.

Ning, X.F., L.M. Xiong, X.L. Wang, X.W. Gao, Z.Q. Zhang, L. Zhong, and G. Li. 2014b. Genetic diversity among Chinese Hami melon and its relationship with melon germplasm of diverse origins revealed by microsatellite markers. Biochem. Syst. Ecol. 57:432-438.

Obandoulloa, J.M., I. Eduardo, A.J. Monforte, and J.P. Fernándeztrujillo. 2009. Identification of QTLs related to sugar and organic acid composition in melon using near-isogenic lines. Scientia Hort. 121:425-433.

Ogawa, M., P. Kay, S. Wilson, and S.M. Swain. 2009. ARABIDOPSIS DEHISCENCE ZONE POLYGALACTURONASE1 (ADPG1), ADPG2, and QUARTET2 are polygalacturonases required for cell separation during reproductive development in Arabidopsis. Plant Cell 21: 216-233.

Perchepied, L., M. Bardin, C. Dogimont, and M. Pitrat. 2005. Relationship between Loci conferring downy mildew and powdery mildew resistance in melon assessed by quantitative trait Loci mapping. Phytopathology 95:556-566.

Périn, C., S. Hagen, C.V. De, N. Katzir, Y. Daninpoleg, V. Portnoy, S. Baudraccoarnas, J. Chadoeuf, C. Dogimont, and M. Pitrat. 2002. A reference map of Cucumis melo based on two recombinant inbred line populations. Theor. Appl. Genet. 104:1017-1034.

Persson, S., A. Paredez, A. Carroll, H. Palsdottir, M. Doblin, P. Poindexter, N. Khitrov, M. Auer, and C.R. Somerville. 2007. Genetic evidence for three unique components in primary cell-wall cellulose synthase complexes in Arabidopsis. Proc. Natl. Acad. Sci. USA 104:15566-15571.

Porebski, S., L.G. Bailey, and B.R. Baum. 1997. Modification of a CTAB DNA extraction protocol for plants containing high polysaccharide and polyphenol components. Plant Mol. Biol. Rptr. 15:8-15.
Ramamurthy, R.K. and B.M. Waters. 2015. Identification of fruit quality and morphology QTLs in melon (Cucumis melo L.) using a population derived from flexuosus and cantalupensis botanical groups. Euphytica 204:163-177.

Ritschel, P.S., T.C.D.L. Lins, R.L. Tristan, G.S.C Buso, J.A. Buso, and M.E. Ferreira. 2004. Development of microsatellite markers from an enriched genomic library for genetic analysis of melon (Cucumis melo L.). BMC Plant Biol. 4:9-24.

Sabato, D., C. Esteras, O. Grillo, B. Picó, and G. Bacchetta. 2015. Seeds morpho-colourimetric analysis as complementary method to molecular characterization of melon diversity. Scientia Hort. 192:441-452.

Tanaka, K., C.J. Stevens, S. Iwasaki, Y. Akashi, E. Yamamoto, T.P. Dung, H. Nishida, D.Q. Fuller, and K. Kato. 2016. Seed size and chloroplast DNA of modern and ancient seeds explain the establishment of Japanese cultivated melon (Cucumis melo L.) by introduction and selection. Genet. Resources Crop Evol. 63:1237-1254.

Tatusov, R.L., M.Y. Galperin, D.A. Natale, and E.V. Koonin. 2000. The COG database: A tool for genome-scale analysis of protein functions and evolution. Nucl. Acids Res. 28:33-36.

Taylor, N.G., R.M. Howells, A.K. Huttly, K. Vickers, and S.R. Turner. 2003. Interactions among three distinct CesA proteins essential for cellulose synthesis. Proc. Natl. Acad. Sci. USA 100:1450-1455.

Tian, G., H. Miao, Y. Yang, J. Zhou, H. Lu, Y. Wang, B. Xie, S. Zhang, and X. Gu. 2016. Genetic analysis and fine mapping of Watermelon mosaic virus resistance gene in cucumber. Mol. Breeding 36:131-142.

Tomason, Y., P. Nimmakayala, A. Levi, and U.K. Reddy. 2013. Map-based molecular diversity, linkage disequilibrium and association mapping of fruit traits in melon. Mol. Breeding 31:829-841.

Voorrips, R.E. 2002. MapChart: Software for the graphical presentation of linkage maps and QTLs. J. Hered. 93:77-78.

Wang, M., H. Miao, S.P. Zhang, S.L. Liu, S.Y Dong, Y. Wang, and G.U. Xing-Fang. 2014. Inheritance analysis and QTL mapping of cucumber seed size. Scientia Agricultura Sinica 41:63-72. (in chinese with English abstr.).
Wang, S., C. Basten, and Z. Zeng. 2012. Windows QTL Cartographer v2.5. Department of Statistics, North Carolina State Univ., Raleigh, NC. $<$ http://statgen.ncsu.edu/qtlcart/WQTLCart.htm>.

Wang, X.L., X.W. Gao, G. Li, H.L. Wang, S.D. Geng, F. Kang, and X.X. Nie. 2011. Construction of a melon genetic map with fruit and seed QTLs. Hereditas 33:1398-1408.

Wang, Y.H., D.H. Wu, J.H. Huang, S.J. Tsao, K.K. Hwu, and H.F. Lo. 2016. Mapping quantitative trait loci for fruit traits and powdery mildew resistance in melon (Cucumis melo). Bot. Stud. 57:19-31.

Wolf-Rüdiger, S., E. Ravit, R. Todd, D. Deborah, and S. Chris. 2001. Modifications of cellulose synthase confer resistance to isoxaben and thiazolidinone herbicides in Arabidopsis IxrI mutants. Proc. Natl. Acad. Sci. USA 98:1007910086.

Yao, Y., K. Li, H. Liu, R.W. Duncan, S. Guo, L. Xiao, and D. Du. 2017. Whole-genome resequencing and fine mapping of an orange petal color gene (Bnpcl) in spring Brassica napus $\mathrm{L}$. to a 151-kb region. Euphytica 213:165-177.

Ye, W.Z., S. Liu, H.Y. Ma, H.Y. Liu, G.Y. Li, and F.S. Luan. 2017. QTL analysis on related seed traits in melon based on CAPS markers. Northern Hort. 12:119-128. (in chinese with English abstr.).

Yi, R., C. Mcgregor, Z. Yan, G. Gong, H. Zhang, S. Guo, H. Sun, W. Cai, Z. Jie, and X. Yong. 2014. An integrated genetic map based on four mapping populations and quantitative trait loci associated with economically important traits in watermelon (Citrullus lanatus). BMC Plant Biol. 14:1-11.

Yuste-Lisbona, F.J., C. Capel, E. Sarria, R. Torreblanca, M.L. Gómez-Guillamón, J. Capel, R. Lozano, and A.I. López-Sesé. 2011. Genetic linkage map of melon (Cucumis melo L.) and localization of a major QTL for powdery mildew resistance. Mol. Breeding 27:181-192.

Zhang, C., Y. Ren, S. Guo, H. Zhang, G. Gong, Y. Du, and Y. Xu. 2013. Application of comparative genomics in developing markers tightly linked to the $P m-2 F$ gene for powdery mildew resistance in melon (Cucumis melo L.). Euphytica 190:157-168.

Zhu, Z.C., M.L. Gao, P. Gao, and F.S. Luan. 2011. QTL analysis of the first fertile flower node of Cucumis melo L. Acta Horticulturae Sinica 38:1753-1760. (in chinese with English abstr.). 
A

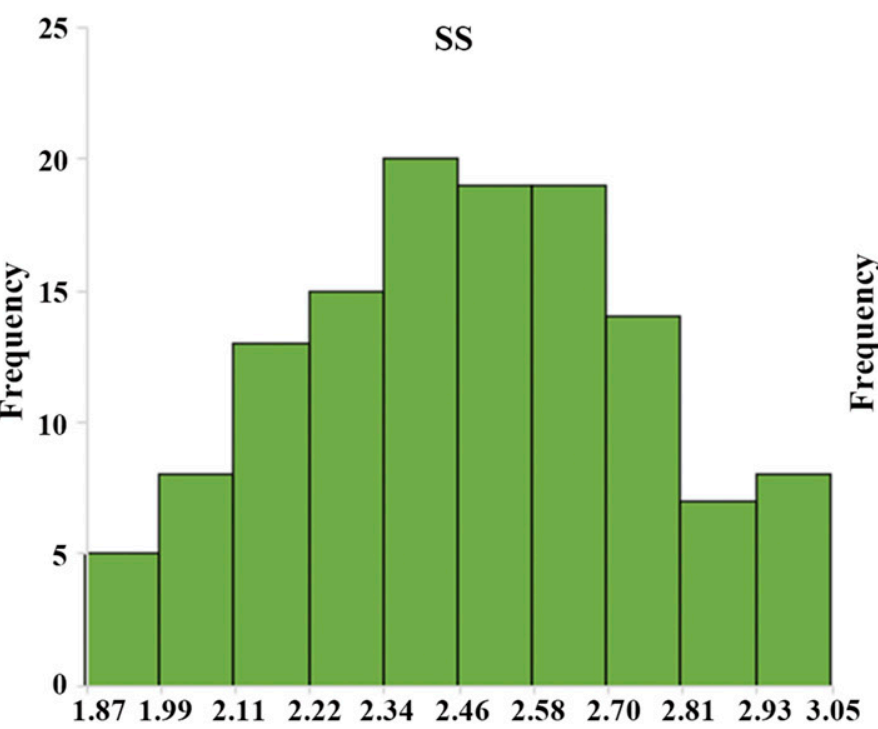

B
25

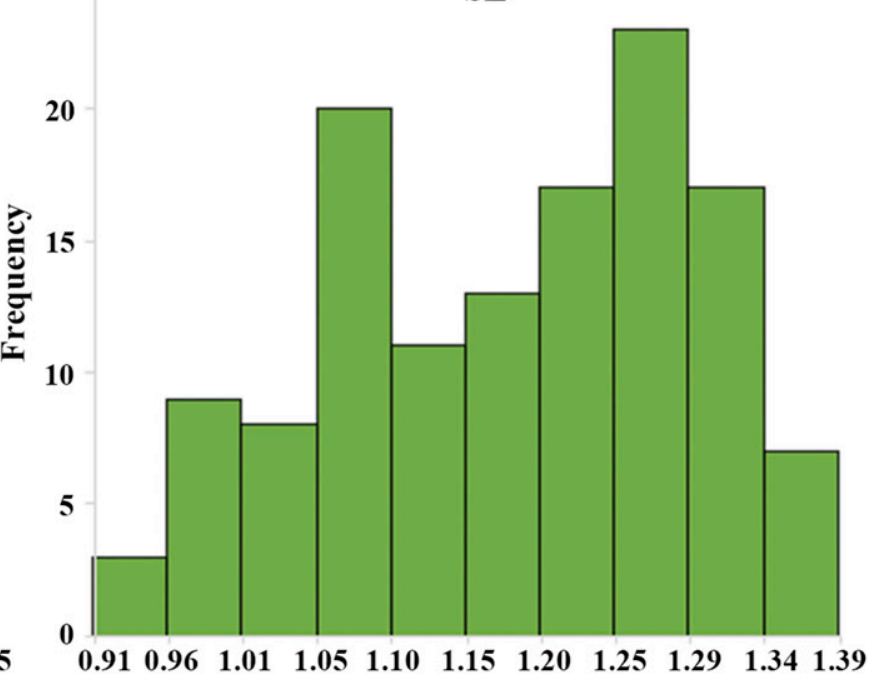

C 30

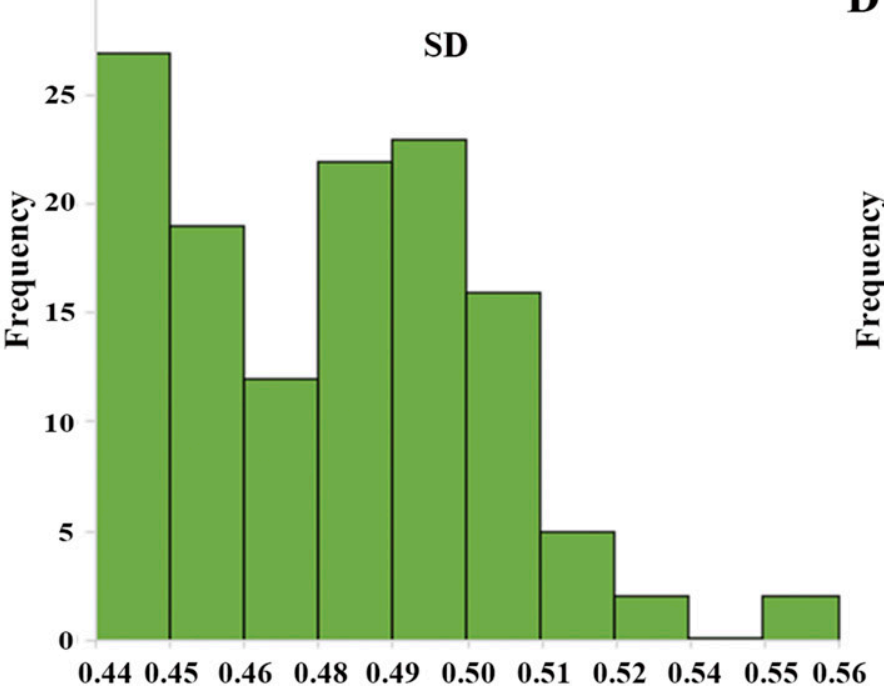

D

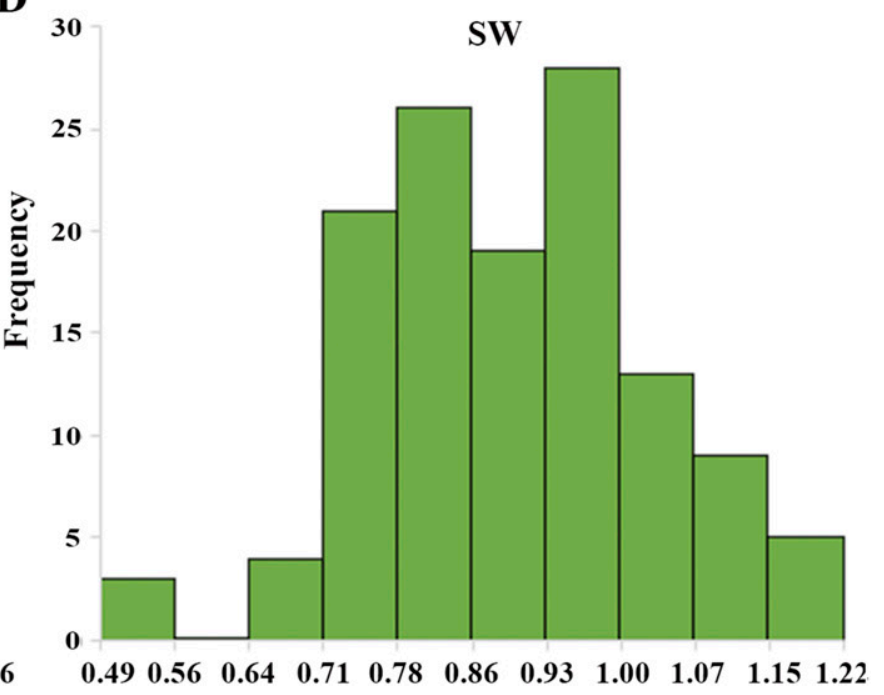

Supplemental Fig. 1. Frequency distribution of (A) SS (seed length-to-width ratio), (B) SL (seed length in centimeter), (C) SD (seed width in centimeters), and (D) $\mathrm{SW}$ (seed weight in grams) phenotypic traits for the $128 \mathrm{BC}_{1} \mathrm{P}_{1}$ individuals as depicted by the histogram. 
LG1

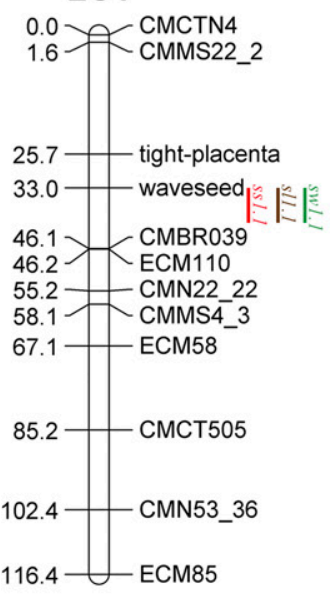

LG7

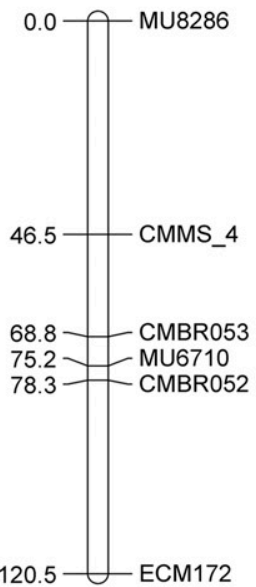

LG2

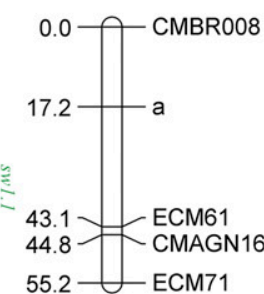

$\begin{array}{ll}57.8 & \text { MU5023 } \\ 61.0 & \text { MU3659 }\end{array}$ 66.0 MU4452 80.3- ECM205

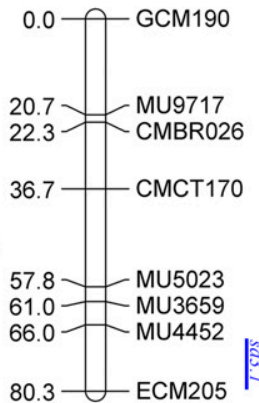

LG4

0.0 - ECM113

6.9- - CMBR089

99

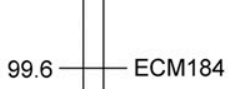

$169.2-$ CMTCN44

\section{LG9}

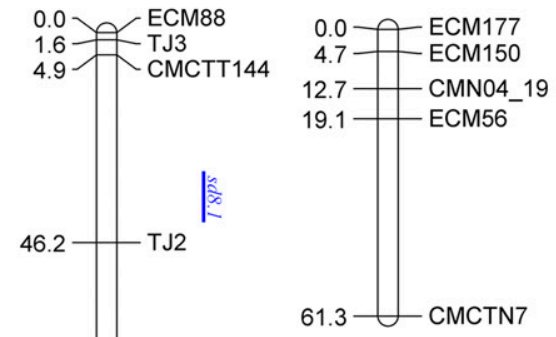

\section{LG10a}

$0.0-14.4-\begin{aligned} & \text { CMBR } 115 \\ & \text { CMCTN71 } \\ & \text { CSWCT01 }\end{aligned}$

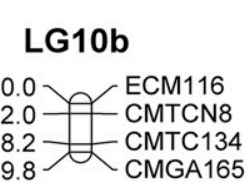

LG5

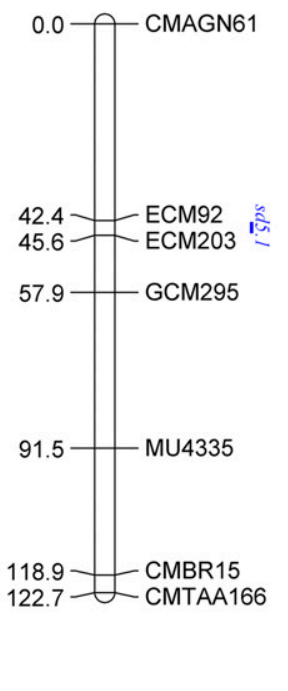

LG11

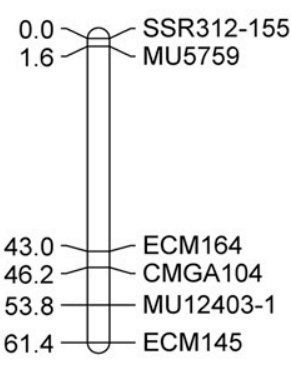

LG6

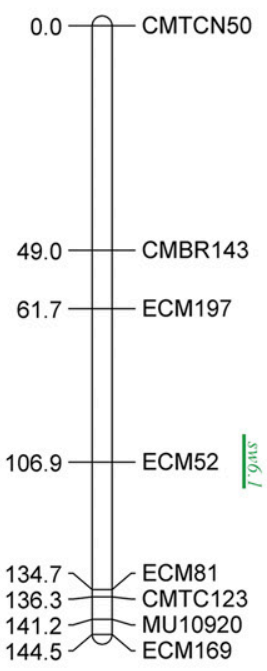

LG12

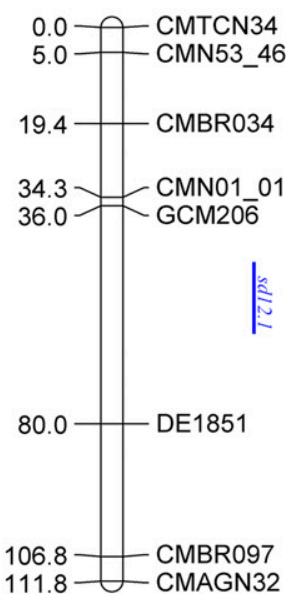

Supplemental Fig. 2. Positions of quantitative trait locus (QTLs) for seed traits detected in MR-1 and 'Queen' $\mathrm{BC}_{1} \mathrm{P}_{1}$ population. The markers are shown to the right of the linkage groups and distances between markers are indicated in centimorgans to the left. QTL nomenclature for traits is given as in Table 3. 


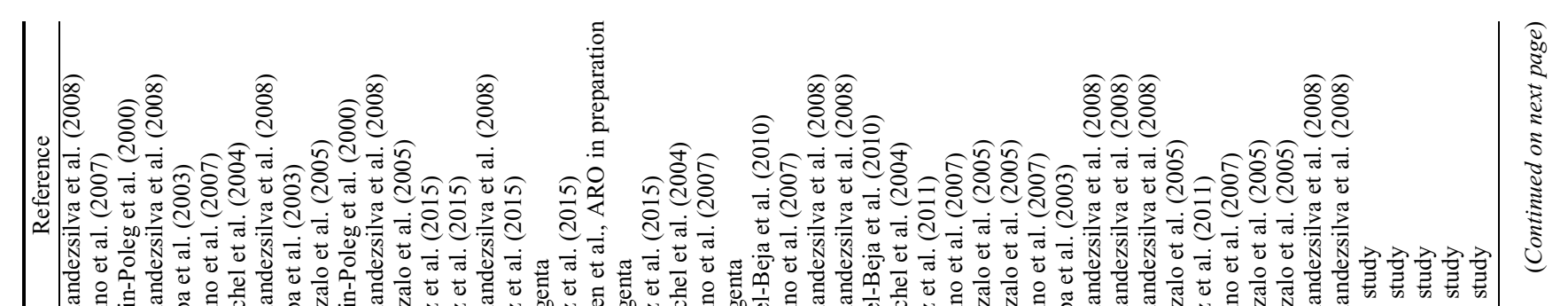

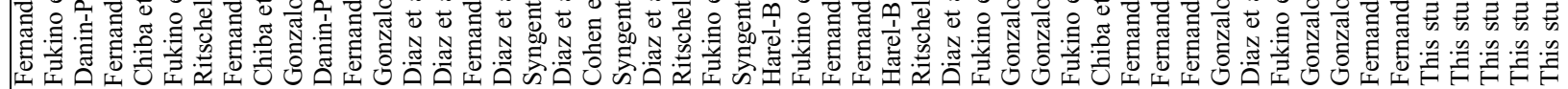

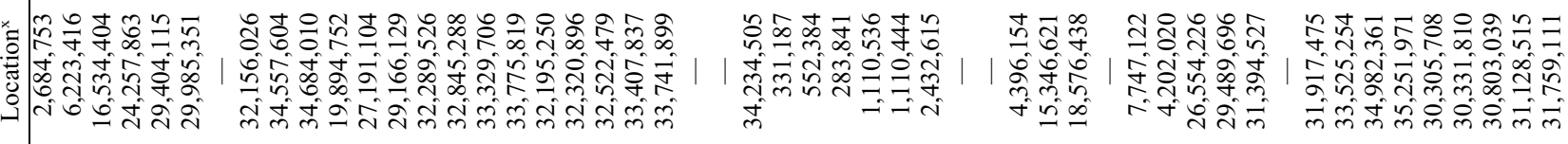

产

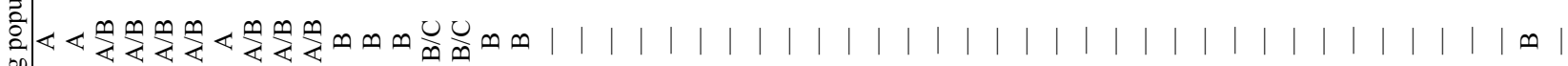
.0

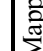

을

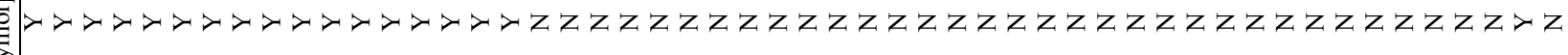
$\stackrel{2}{2}$

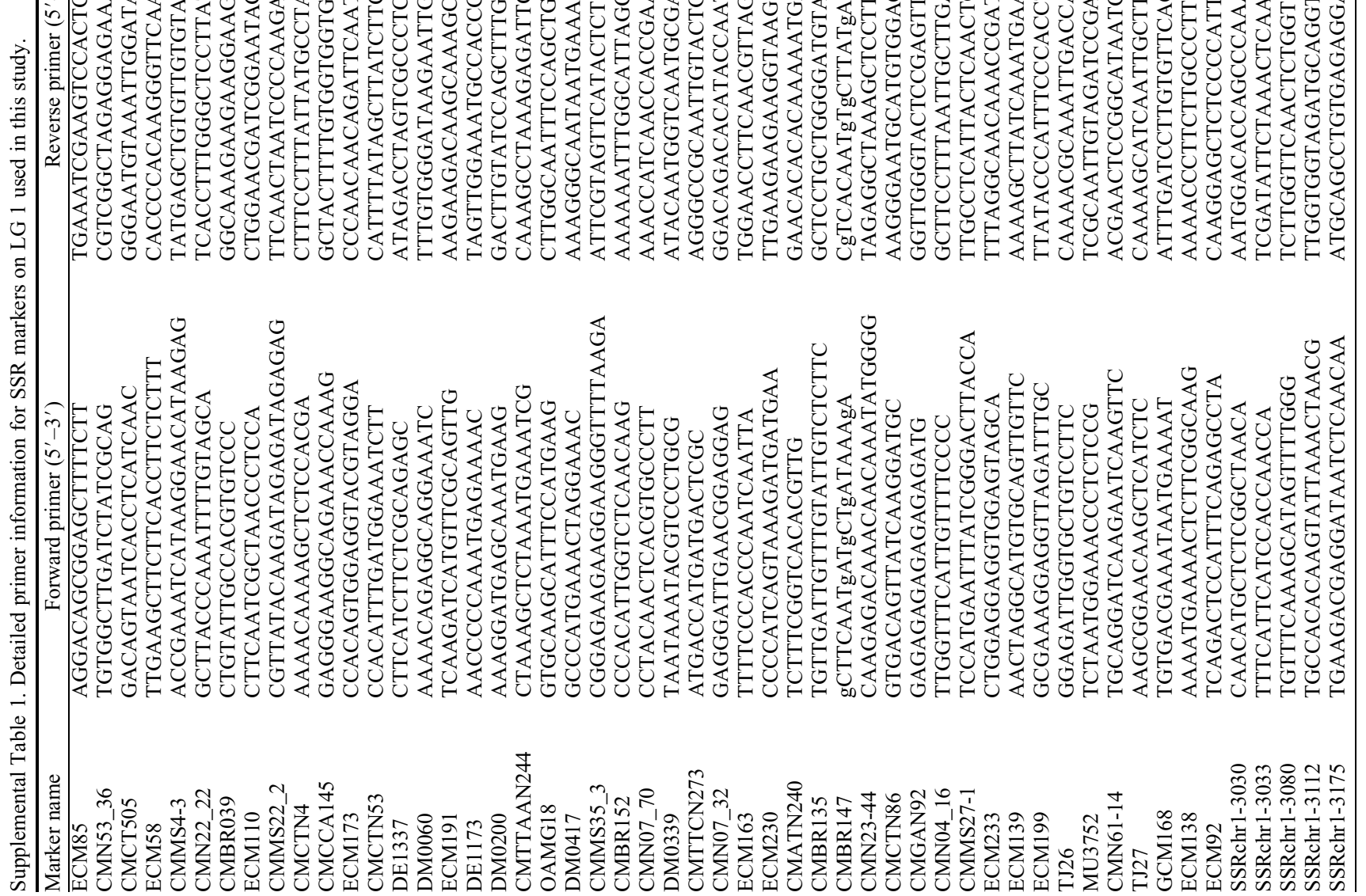




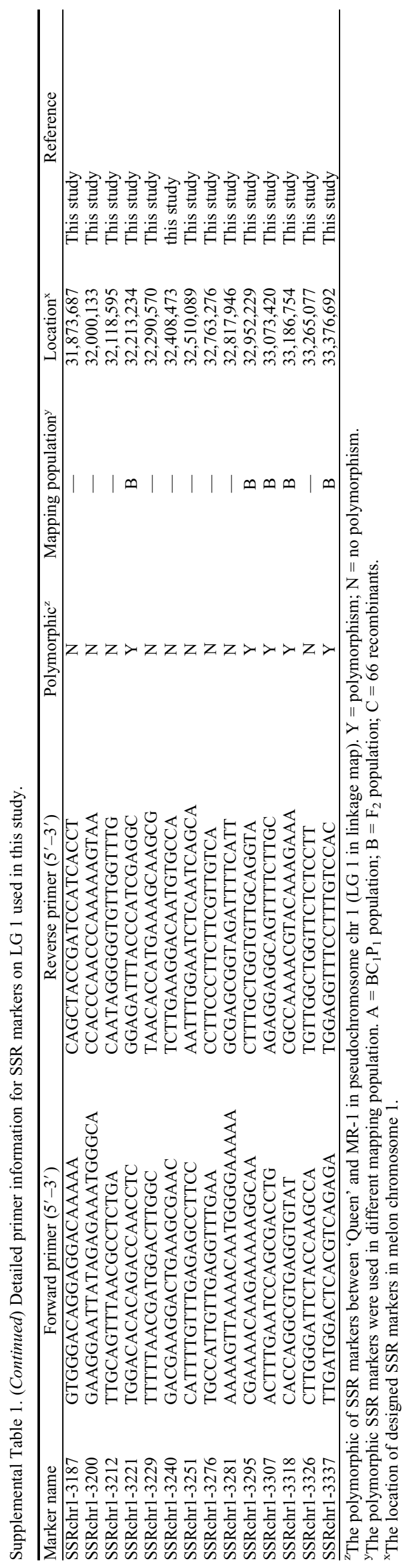


Supplemental Table 2. Pearson's correlation analyses for seed size traits.

\begin{tabular}{lcccc}
\hline Trait & SS & SL & SD & SW \\
\hline SS & & $0.873^{* *}$ & $-0.400^{* *}$ & 0.071 \\
SL & $0.873^{* *}$ & & 0.091 & $0.187^{*}$ \\
SD & $-0.400^{* *}$ & 0.091 & & $0.215^{*}$ \\
SW & 0.071 & $0.187^{*}$ & $0.215^{*}$ & \\
\hline
\end{tabular}

$*$,**Significant at the 0.05 and 0.01 levels, respectively.

SL, SD, and SW indicate seed length, width, and weight, respectively; SS indicates length-to-width ratio.

Supplemental Table 3. Information of InDel markers designed for fine mapping; all the markers located on CM3.5_scaffold00060 of the melon genome.

\begin{tabular}{|c|c|c|c|c|}
\hline Marker name & Location & Forward primer $\left(5^{\prime}-3^{\prime}\right)$ & Reverse primer $\left(5^{\prime}-3^{\prime}\right)$ & Mapping population \\
\hline InDelchr1-3232 & $32,327,022$ & ATAACTCACTGCTTGGAT & TAGTGTCTATTGTCATCG & $\mathrm{C}$ \\
\hline InDelchr1-3240 & $32,409,633$ & TACGAAGGTAAACTCACA & GTCCTCAACTCATAACAT & $\mathrm{C}$ \\
\hline InDelchr1-3241 & $32,414,205$ & CTGAACCGATTATTGACG & AAGTTTGCTTCCGACTGC & $\mathrm{C}$ \\
\hline InDelchr1-3250 & $32,503,971$ & ACATTCAACCAGATAAAA & TAATATGAGATAAGGGAA & $\mathrm{C}$ \\
\hline InDelchr1-3259 & $32,594,101$ & TATGCTGCTAATCAAATGTC & CATAGAAAGGGAGGGAGA & $\mathrm{C}$ \\
\hline InDelchr1-3267 & $32,677,062$ & GATGGTAGGAAGTTTTAGGGTT & TGGCAGGACTAATTCAGCAC & $\mathrm{C}$ \\
\hline InDelchr1-3228 & $32,289,584$ & TTTATGGTGATTGGGACT & CGATGGCTGATGAACTCT & - \\
\hline InDelchr1-3234 & $32,346,404$ & GTTTGGAAATTAGGAGAT & TGCATAGTATTGGGAGTT & - \\
\hline InDelchr1-3245 & $32,455,202$ & CGGAGATGGTCTAGCAAA & CAGTGGCGAATGAATGTG & - \\
\hline InDelchr1-3252 & $32,526,057$ & TATGCTGAATTTGGTGAG & TTTAGTTGGTGGGCTTTA & - \\
\hline InDelchr1-3261 & $32,610,065$ & ATTAGAATGAGAAACGAT & TATTTGATGTCCATTAGT & - \\
\hline InDelchr1-3276 & $32,763,448$ & GAGATGGGTTTGGTTTGA & CTTCCCTTCTTCGTTGTC & - \\
\hline InDelchr1-3280 & $32,808,660$ & СТTAАТТTССТТАСССТТ & TACACCTTATACCGTTTC & - \\
\hline
\end{tabular}

${ }^{\mathrm{z}}$ The polymorphic SSR markers were used in different mapping population. $\mathrm{A}=\mathrm{BC} 1 \mathrm{P} 1$ population; $\mathrm{B}=\mathrm{F}_{2}$ population $\mathrm{C}=66$ recombinants. 
Supplemental Table 4. Results of wave seed and tight-placenta candidate gene prediction and annotation.

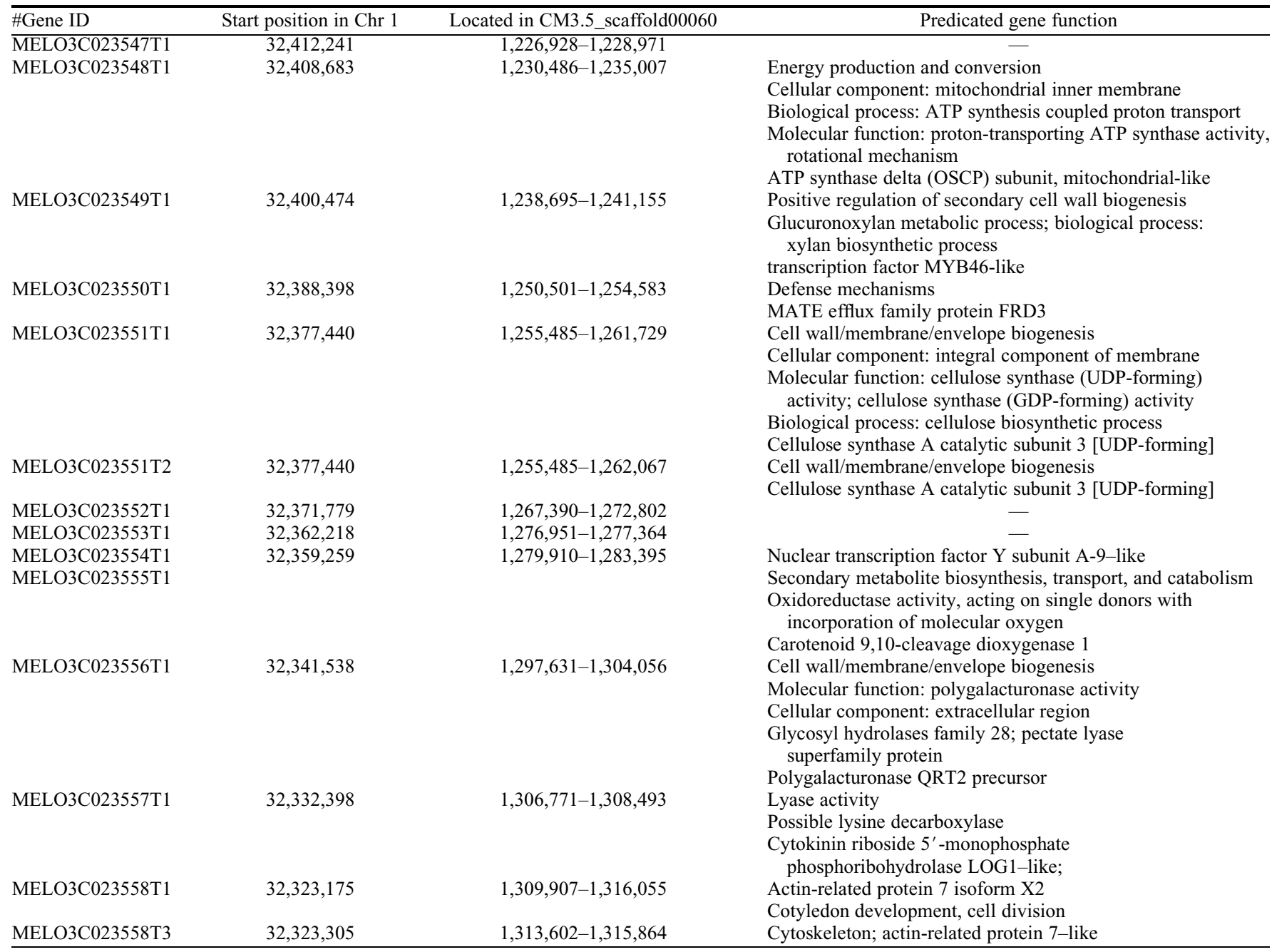

Supplemental Table 5. The SNP variations of 'Queen' and MR-1 melon accessions in candidate genes.

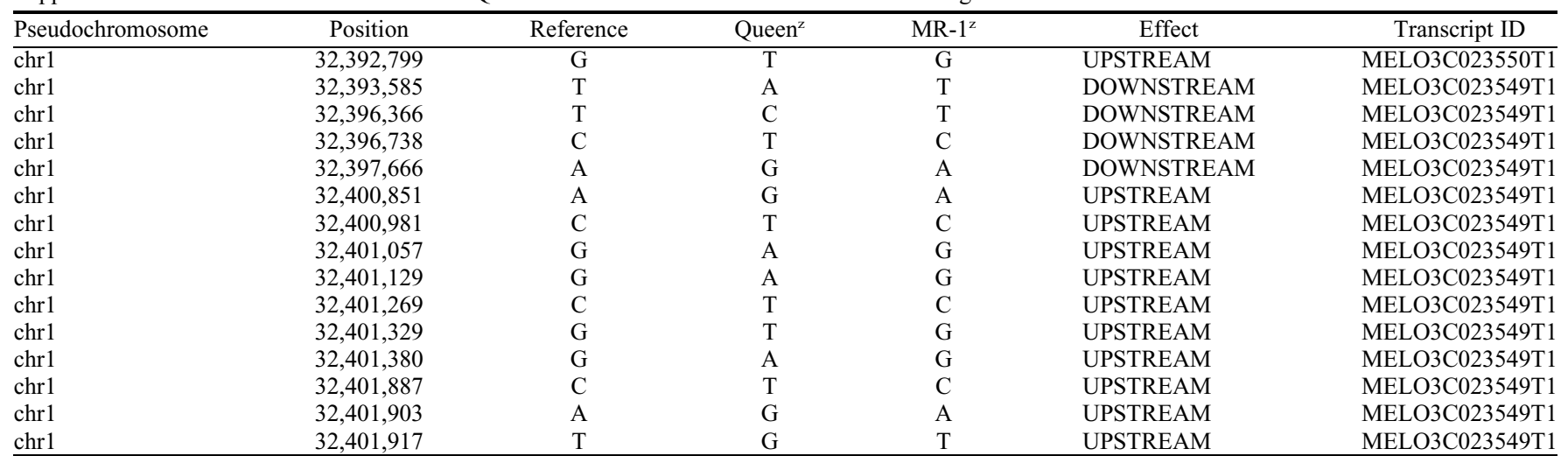

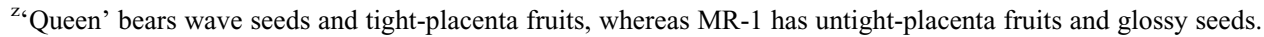




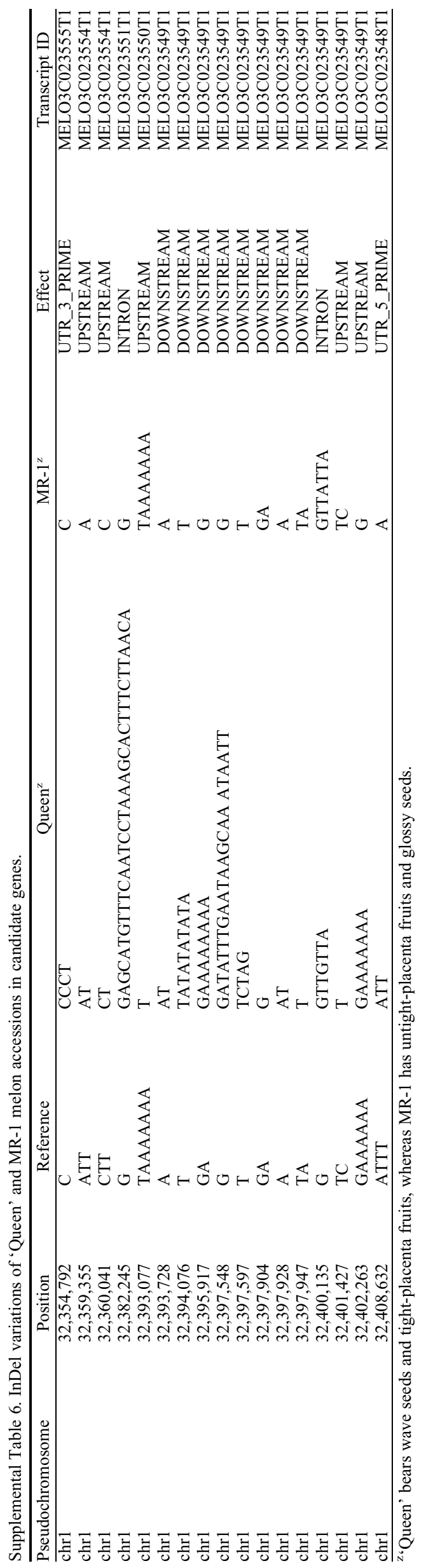

HortScience Vol. 53(6) June 2018 